\title{
Open arch reconstruction in the endovascular era: Analysis of 721 patients over 17 years
}

\author{
Himanshu J. Patel, MD, Christopher Nguyen, BS, Amy C. Diener, RN, BSN, Mary C. Passow, RN, BSN, \\ Diane Salata, RN, BSN, and G. Michael Deeb, MD
}

Objective: Recent advancements in thoracic endovascular aortic repair, such as branched endografts or hybrid debranching/thoracic endovascular aortic repair, have extended the option of endoluminal therapy into the realm of the aortic arch. A contemporary assessment of open arch repair to provide long-term data for comparative analysis for these newer therapies is timely, warranted, and presented in this article.

\begin{abstract}
Methods: Since the inception of our thoracic endovascular aortic repair program in 1993, 721 patients (mean age of 59.3 years, $68.9 \%$ were male) have undergone median sternotomy and open arch reconstruction with hypothermic circulatory arrest. Extended arch repair was performed in $42.7 \%$ with construction of bypasses to the innominate (296 patients), left carotid (216 patients), and subclavian (75 patients) arteries or elephant trunk procedures (42 patients). Concomitant aortic valve or aortic root replacement was required in 403 patients, and root reconstruction was required in 222 patients. Retrograde (641 patients) or antegrade (400 patients) cerebral perfusion was used for neuroprotection during hypothermic circulatory arrest. The operative procedure was urgent or emergency in 316 patients (43.8\%) and included repair of type A dissection in 284 patients $(39.3 \%)$. A total of 111 patients $(15.4 \%)$ had undergone prior cardiac surgery. Primary outcomes in this study were early and late mortality. Follow-up was $100 \%$ complete (mean, 52.6 months).
\end{abstract}

Results: Thirty-day morbidity included death (36 patients [5\%]), stroke (34 patients [4.7\%]), and permanent dialysis (14 patients [1.9\%]). Independent predictors of early mortality included advancing age, prolonged bypass times, and impaired ejection fraction (all $P<.05$ ). Actuarial survival at 10 years was $65 \%$. Independent predictors of late mortality included advancing age, prolonged lower body circulatory arrest times, and increasing creatinine (all $P<.05$ ). By Kaplan-Meier analysis, 10 -year survival was significantly reduced after operative procedures for type A dissection (non-type A $69.1 \%$ vs type A 58\%, $P=.003$ ). Freedom from aortic reoperation (any segment) was $72.6 \%$ at 10 years.

Conclusions: Open aortic arch repair can be accomplished with excellent early and late results. These outcomes provide objective data for comparison and suggest that newer endovascular therapies should be evaluated first in high-risk groups, such as those with advanced age or impaired renal function before broader application in all patients. (J Thorac Cardiovasc Surg 2011;141:1417-23)

In the century since Sir William Osler remarked that "there is no disease more conducive to clinical humility than aneurysm of the aorta," dramatic advances have occurred in the field of aortic surgery. After the pioneering work by DeBakey and colleagues in $1957,{ }^{1}$ mortality for arch reconstruction exceeded $25 \%$, with cause of death often secondary to neurologic complications. The introduction of deep hypothermic circulatory arrest (HCA) by Griepp and colleagues ${ }^{2}$

From the Department of Surgery, University of Michigan Cardiovascular Center, Ann Arbor, Mich.

Disclosures: Authors have nothing to disclose with regard to commercial support.

Read at the 90th Annual Meeting of The American Association for Thoracic Surgery, Toronto Ontario, Canada, May 1-5, 2010.

Received for publication May 4, 2010; revisions received Feb 10, 2011; accepted for publication Feb 18, 2011; available ahead of print April 4, 2011.

Address for reprints: Himanshu J. Patel, MD, Assistant Professor of Surgery, Section of Cardiac Surgery, CVC Room 5144, 1500 E. Medical Center Drive SPC 5864, Ann Arbor, MI (E-mail: hjpatel@med.umich.edu).

$0022-5223 / \$ 36.00$

Copyright (c) 2011 by The American Association for Thoracic Surgery

doi:10.1016/j.jtcvs.2011.02.020 simplified the operative approach and established a safe strategy for neuroprotection. Seminal work by Svensson and associates ${ }^{3}$ in 1993 demonstrated that these techniques used in 656 patients could result in death and stroke rates of $10 \%$ and $7 \%$, respectively.

Since this landmark report, the introduction of endovascular techniques has revolutionized the therapy of thoracic aortic disease..$^{4-7}$ Although initially applied to degenerative aneurysms confined to the abdominal and descending thoracic aorta (thoracic endovascular aortic repair [TEVAR]), recent work has extended the use of this approach to the arch aorta. ${ }^{4,5}$ Moreover, in an effort to reduce the perceived morbidity associated with HCA, complex extra-anatomic arch vessel bypass and endovascular repair, that is, debranching procedures and evolving technology including branched endografts, have extended TEVAR into the ascending aorta. ${ }^{7,8}$ The long-term results of endovascular repairs with or without debranching are still unclear. It is in this context that a contemporary analysis of open aortic arch reconstruction focusing on both early and 


$$
\begin{aligned}
& \text { Abbreviations and Acronyms } \\
& \begin{aligned}
\mathrm{ACP} & =\text { antegrade cerebral perfusion } \\
\mathrm{CI} & =\text { confidence interval } \\
\mathrm{HCA} & =\text { hypothermic circulatory arrest } \\
\mathrm{HR} & =\text { hazard ratio } \\
\mathrm{OR} & =\text { odds ratio } \\
\mathrm{RCP} & =\text { retrograde cerebral perfusion } \\
\mathrm{TEVAR} & =\text { thoracic endovascular aortic repair }
\end{aligned}
\end{aligned}
$$

late outcomes is warranted. The study period chosen in this study reflects the endovascular era at the University of Michigan, which commenced in 1993.

\section{MATERIALS AND METHODS}

This study was approved by the institutional review board of the University of Michigan Hospitals (study 2003-0128). Informed consent requirements were waived for this study.

A retrospective analysis of data from all patients admitted to the University of Michigan Hospitals from 1993 to 2009 who underwent aortic replacement was performed. Criteria for entry into the study cohort consisted of (1) approach via a median sternotomy; (2) resection into the arch aorta (ie, exclusion of open distal anastomosis without arch reconstruction); and (3) use of deep HCA (eg, exclusion of patients undergoing great vessel bypass for obstructive arch disease). With the use of these inclusion criteria, 721 consecutive patients constituted the study cohort. A combination of clinic and hospital records, data from the prospectively collected Society of Thoracic Surgeons database, imaging studies, and query of the National Death Index were used to obtain early and long term information.

\section{Operative Technique}

After median sternotomy and institution of cardiopulmonary bypass, patients were cooled to $18^{\circ} \mathrm{C}$ nasopharyngeal and bladder temperature with the maximum temperature gradient between perfusate and body temperature kept at less than $10^{\circ} \mathrm{C}$ (for both cooling and later rewarming). During this time, root reconstruction was initiated if necessary. Neuroprotective adjuncts, including $25 \mathrm{~g}$ mannitol, $1 \mathrm{~g}$ methylprednisolone, and $1 \mathrm{~g}$ thiopental, were administered just before institution of HCA. The aorta was then opened, and the site of distal anastomosis was identified. Retrograde cerebral perfusion (RCP) was initiated at this time in 641 patients $(89 \%)$, with flows of 500 to $800 \mathrm{~mL} / \mathrm{min}$ titrated to a central venous pressure of 35 $\mathrm{mm} \mathrm{Hg}$. With proximal hemiarch resection, HCA with RCP alone was often used, and RCP then was discontinued only after reinstitution of cardiopulmonary bypass to prevent air embolism into the brain. If prolonged HCA times were expected either on the basis of pathology or the need to extend arch resection to include great vessels, antegrade cerebral perfusion (ACP) was used at flow rates of 750 to $1000 \mathrm{~mL} / \mathrm{min}$ titrated to keep the pressure in the right radial arterial line at $80 \mathrm{~mm} \mathrm{Hg}$ by selective cannulation of the innominate and left carotid arteries or by axillary arterial perfusion with left carotid artery selective cannulation. In this instance, RCP was then discontinued only after initiation of ACP to prevent air embolism. Rewarming was initiated after completion of the open distal anastomosis, and flow was restored to the lower body. Great vessel reimplantation was performed as an island until 2001, after which each vessel was bypassed separately using a customized Dacron graft with multiple prefabricated side branches as previously described. The graft was then sized to an appropriate length, and a proximal anastomosis was performed. When normothermic, the patient was weaned from cardiopulmonary bypass as tolerated.

\section{Statistical Methods}

Early outcomes of interest included 30-day or in-hospital rates of mortality, stroke, and renal failure requiring dialysis. The primary late outcome of interest was survival time and vital status. Early mortality was defined as that occurring within 30 days of operation or in-hospital death. Late mortality was defined as that occurring thereafter. Follow-up was $100 \%$ complete up to April 2010 for the primary outcome of late mortality with a mean of $52.6 \pm 39.9$ months.

Data were analyzed using SPSS (SPSS Inc, Chicago, Ill). All data are expressed as mean \pm standard deviation where applicable. Dichotomous variables were evaluated using chi-square analysis, and continuous variables were evaluated using independent $t$ tests. Multivariate models (binary logistic regression for early outcomes and Cox proportional hazards for late outcomes) were constructed using a forward conditional process to identify factors that were independently associated with each of the outcomes of interest. The factors used in the multivariate analysis included those with a $P$ value of 0.1 or less on univariate analysis. Results were expressed with odds ratios (ORs) or hazard ratios (HRs) with $95 \%$ confidence intervals (CIs). Survival was analyzed by Kaplan-Meier methods, with comparison of survival curves performed with the log-rank test.

\section{RESULTS}

The mean age of the study cohort was $59.3 \pm 13.9$ years (68.9\% were male). Demographics and comorbidities are listed in Table 1. Indications for intervention included type A dissection in 284 patients and fusiform aneurysm in 416 patients. Arch repair was performed in the reoperative setting in 111 patients $(15.4 \%)$; details regarding prior aortic or cardiac procedures are listed in Table 1 . The procedure was elective in 404 patients $(56 \%)$, urgent in 128 patients $(17.8 \%)$, and emergency in 188 patients $(26.1 \%)$.

\section{Early Results}

Early mortality was seen in 36 patients $(5.0 \%)$. By multivariate analysis, older age $(P=.001 ; \mathrm{OR}, 1.07$; CI, 1.0-1.2), lower ejection fraction $(P=.02$; OR, 0.97 ; CI, $0.95-0.99)$, prolonged cardiopulmonary bypass $(P<.0001$; OR, 1.01; CI, 1.007-1.02), and HCA time ( $P=.02$; OR, 1.03; CI, 1.004-1.05) were independently associated with early mortality. In an attempt to identify whether era of the operative procedure affected mortality, the entire study period was divided into 2 segments: era 1 (1993 to March $2005, \mathrm{n}=316$ ), representing the initial time when endovascular repair (TEVAR) was available only on a limited basis at the University of Michigan Cardiovascular Center for compassionate use or as part of Food and Drug Administrationsponsored clinical trials; and era 2 (April 2005-2009, $\mathrm{n}=369$ ), when TEVAR was widely available. Although the mortality rates were different on univariate analysis (era $1: \mathrm{n}=23,7.3 \%$ vs era $2: \mathrm{n}=13,3.5 \%, P=.04$ ), multivariate analysis did not identify era of operation as an independent risk factor for death.

Stroke was identified in 34 patients $(4.7 \%)$. Univariate predictors of postoperative stroke included the history of coronary artery disease, chronic obstructive pulmonary disease, reduced ejection fraction or elevated creatinine, urgent or emergency operative status, repair of acute type A 
TABLE 1. Patient characteristics

\begin{tabular}{|c|c|}
\hline Variable & Frequency $(\%)$ \\
\hline \multicolumn{2}{|l|}{ Preoperative demographics } \\
\hline Age (y) & $59.3 \pm 13.9$ \\
\hline Male gender & $497(68.9 \%)$ \\
\hline History of tobacco use & $377(52.2 \%)$ \\
\hline Diabetes & $51(7.1 \%)$ \\
\hline Hypertension & $464(64.4 \%)$ \\
\hline Cerebrovascular accident & $32(4.4 \%)$ \\
\hline Mean preoperative creatinine (mg/dL) & $1.1 \pm 0.7$ \\
\hline History of connective tissue disease & $22(3.1 \%)$ \\
\hline Peripheral vascular occlusive disease & $67(9.3 \%)$ \\
\hline Coronary artery disease & $145(20.1 \%)$ \\
\hline Congestive heart failure & $88(12.3 \%)$ \\
\hline Preoperative ejection fraction $(\%)$ & $52.5 \% \pm 14 \%$ \\
\hline Elective status of operation & $404(56.0 \%)$ \\
\hline Maximum aortic diameter & $5.7 \pm 1.2$ \\
\hline Diagnosis of acute type A dissection & $284(39.4 \%)$ \\
\hline Prior $\mathrm{CABG}$ & $29(4.0 \%)$ \\
\hline Prior aortic valve/root replacement & $85(11.8 \%)$ \\
\hline Prior ascending thoracic aortic repair & $23(3.2 \%)$ \\
\hline Prior descending aortic repair & $9(1.3 \%)$ \\
\hline \multicolumn{2}{|l|}{ Intraoperative variables } \\
\hline Aortic valve/root replacement & $403(55.9 \%)$ \\
\hline Aortic valve resuspension & $222(30.1 \%)$ \\
\hline Isolated arch procedure & $14(1.9 \%)$ \\
\hline Extended arch procedure & $308(42.7 \%)$ \\
\hline Innominate artery bypass & $296(41.1 \%)$ \\
\hline Left carotid artery bypass & $216(30.0 \%)$ \\
\hline Left subclavian artery bypass & $75(10.4 \%)$ \\
\hline Descending aortic repair & $24(3.3 \%)$ \\
\hline Elephant trunk procedure & $42(5.8 \%)$ \\
\hline $\mathrm{CABG}$ & $91(12.6 \%)$ \\
\hline Mitral valve repair/replacement & $21(2.9 \%)$ \\
\hline Use of RCP & $641(89.0 \%)$ \\
\hline Use of ACP & $400(55.5 \%)$ \\
\hline Cerebral ischemic time (min) & $16.6 \pm 14.0$ \\
\hline Lower body hypothermic arrest time (min) & $36.6 \pm 15.6$ \\
\hline Cardiopulmonary bypass time (min) & $216.9 \pm 74.3$ \\
\hline Crossclamp time (min) & $168.2 \pm 62.3$ \\
\hline
\end{tabular}

dissection, prolonged HCA time, or need to extend arch resection to include left subclavian artery or proximal descending aorta (all $P<.05$ ). Unlike mortality rates, the occurrence of postoperative stroke was not associated with era of operation (era 1: $\mathrm{n}=14,4.3 \%$ vs era $2: \mathrm{n}=20,5.5 \%, P=.6$ ). By multivariate analysis, independent predictors of stroke included history of chronic obstructive pulmonary disease $(P=.01$; OR, 3.3; CI, $1.3-$ $8.2)$, procedure for type A dissection $(P=.003$, OR, 4.05; CI, 1.6-10.1), prolonged HCA time $(P=.03$; OR, 1.02; CI, 1.002-1.04), resection into the proximal descending aorta $(P=.03$; OR, 4.63; CI, 1.12-19.1), and occurrence of permanent postoperative dialysis $(P=.003$; OR, 7.14; CI, 2.0-26.1).
Other early adverse events included the occurrence of postoperative renal failure in 42 patients $(5.8 \%)$, with permanent dialysis required in only 14 patients $(1.9 \%)$. Prolonged ventilation requiring tracheostomy was also observed in 24 patients $(3.3 \%)$. The median postoperative length of stay was 8 days (interquartile range, 5-14 days) and was independent of era of operation $(P=.86)$.

Of the 685 patients surviving the operative period, 104 $(15.2 \%)$ required admission to a skilled nursing facility $(\mathrm{n}=74)$ or an inpatient rehabilitation unit $(\mathrm{n}=30)$. At last follow-up, 47 patients $(6.9 \%)$ did not return to an independent lifestyle. Independent predictors of permanent disability included advancing age (OR, $1.1 ; P<.0001)$, history of $\mathrm{CHF}(\mathrm{OR}, 2.8 ; P=.007)$ or CVA $(\mathrm{OR}, 3.7 ; P=.02)$, occurrence of postoperative stroke (OR, 6.3; $P<.0001)$, need for tracheostomy (OR, 4.2; $P=.01)$, and dialysis (OR, 5.0; $P=.03$ ).

\section{Late Results}

The crude mortality rate at last follow-up was $21.6 \%$ $(\mathrm{n}=156)$. Variables associated with late mortality are listed in Table 2. The Kaplan-Meier survival curve generated for the entire cohort is shown in Figure 1. Cox proportional hazards analysis identified increasing age $(P<.0001 ; \mathrm{HR}, 1.05)$, preoperative creatinine $(P=.005 ; \mathrm{HR}, 1.57)$, history of coronary artery bypass grafting $(P<.0001, \mathrm{HR}, 5.62)$ or descending aortic replacement $(P=.001 ; \mathrm{HR}, 11.14)$, prolonged circulatory arrest time $(P=.008 ; \mathrm{HR}, 1.021)$, and requirement for postoperative tracheostomy $(P=.032$; $\mathrm{HR}, 3.16)$ as independent predictors of late mortality. Although not identified as an independent risk factor on multivariate analysis, type A dissection did have an important time-dependent effect on mortality (Figure 2). Its primary effects on mortality seem to be exerted in the early postoperative period, but as Figure 2 shows, the survival curves are relatively parallel thereafter.

Freedom from late aortic reoperation at 10 years was $72.6 \%$, and the actuarial curve is presented in Figure 3, A. Procedures at reoperation $(\mathrm{n}=82)$ included open $(43$ patients) or endovascular (11 patients) descending aortic repair, thoracoabdominal aneurysmectomy (11 patients), completion arch procedures (4 patients), abdominal aortic repair (4 patients), and aortic valve or root replacement ( 8 patients). One patient had a repair for an infected pseudoaneurysm at the proximal anastomosis of the ascending graft and dehiscence of the right coronary button from a previous Bentall repair. When evaluated by Cox proportional hazards analysis, independent predictors of late reoperation included an elephant trunk procedure at the time of arch reconstruction $(P<.0001 ; \mathrm{HR}, 9.26)$. The latter was likely a result of the high frequency (13/42 patients [31\%]) in which the elephant trunk procedure was a required firststage operation in anticipation of a predefined secondstage procedure. In addition, an aortic valve or aortic root 
TABLE 2. Univariate predictors of late mortality

\begin{tabular}{lc}
\hline \multicolumn{1}{c}{ Variable } & Univariate $\boldsymbol{P}$ value \\
\hline Age & $<.0001$ \\
Male gender & .064 \\
History of tobacco use & .018 \\
Hypertension & .006 \\
Peripheral vascular occlusive disease & $<.0001$ \\
Coronary artery disease & .042 \\
Congestive heart failure & .005 \\
Status of operation & .003 \\
Maximum aortic diameter & .018 \\
Preoperative creatinine & .009 \\
Prior CABG & .002 \\
Prior descending aortic repair & .004 \\
Preoperative ejection fraction & $<.0001$ \\
Operation for type A dissection & .003 \\
Need for concomitant CABG & .009 \\
Cardiopulmonary bypass times & $<.0001$ \\
Myocardial ischemia times & $<.0001$ \\
Cerebral ischemic times & .002 \\
Lower body circulatory arrest times & $<.0001$ \\
Postoperative stroke & .03 \\
Postoperative need for permanent dialysis & .001 \\
Postoperative tracheostomy & $<.0001$ \\
\hline$C A B G$ Com any
\end{tabular}

$C A B G$, Coronary artery bypass grafting.

replacement at the time of arch reconstruction was independently protective against future aortic events $(P=.003$; HR, $0.5)$. The occurrence of type A dissection did not predict late reoperation (univariate $P=.19$ ). Similarly, KaplanMeier analysis stratified by initial operation for type A dissection did not identify time-dependent effects $(P=.128)$, although the curves crossed early and then separated. This suggested that longer follow-up with more robust numbers may suggest otherwise (Figure 3, $B$ ).

\section{DISCUSSION}

The recent shift in aortic surgery toward endovascular solutions continues to move proximally, with recent work suggesting a reduction in morbidity for descending aortic repair with TEVAR when compared with open repair.9,10 As this technology progresses toward the arch and into the ascending aorta, a contemporary analysis of open arch reconstruction is appropriate to define a comparative group against which the newer technology can be compared and to identify patient populations at high risk who may benefit from a less-invasive approach. It is in this setting that we undertook the current analysis, focusing on the study period that TEVAR was available at the University of Michigan Cardiovascular Center.

The data in this study suggest that open arch reconstruction can be performed safely. Early results suggest that the complications of arch repair (ie, death and stroke) can occur at rates less than $5 \%$. The rates of these complications in

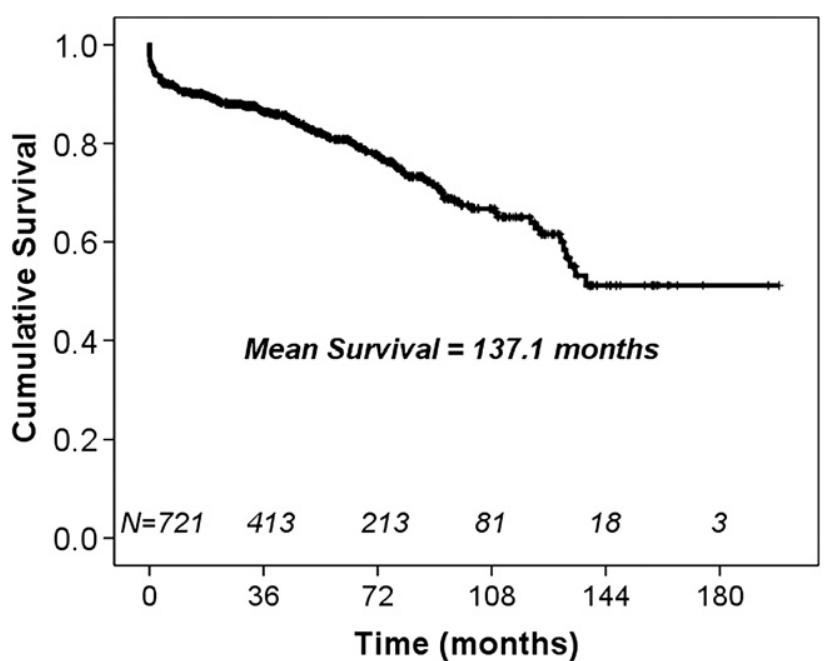

FIGURE 1. Kaplan-Meier survival analysis for the entire cohort. The 12-year survival for the entire cohort is $51.2 \% \pm 0.5 \%$.

our study are comparable to those reported in the contemporary era despite a high frequency of acute type A dissection $(39.3 \%)$, reoperative procedures $(15.4 \%)$, and extended arch repair $(42.7 \%){ }^{11-19}$ Early mortality was dependent on traditional factors, such as perfusion and body circulatory arrest times, but also identified older patients as a potential group in whom to initially apply endovascular solutions. In addition, postoperative stroke was predicted by extent of resection (with resection into the descending aorta as a surrogate marker) or procedure for type A dissection. The use of ACP or RCP did not

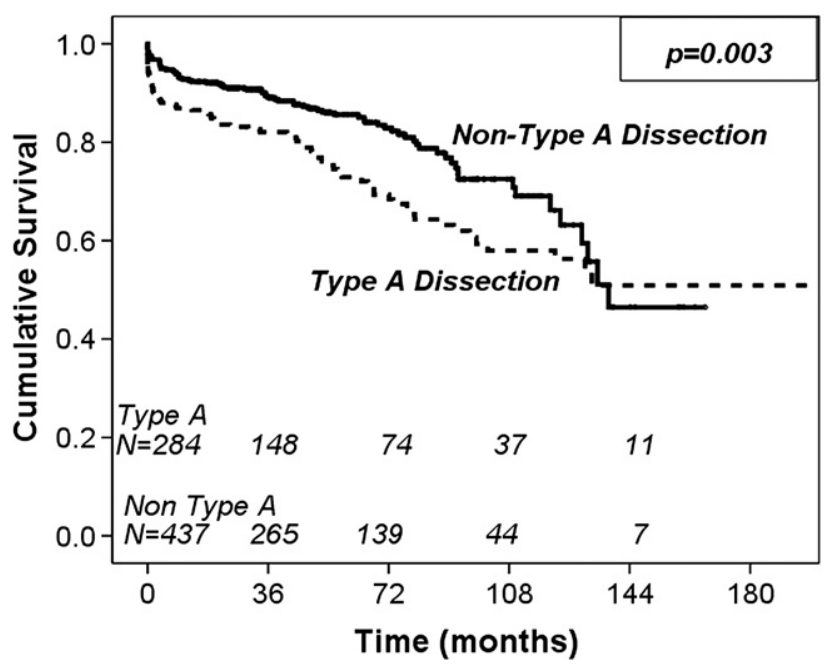

FIGURE 2. Kaplan-Meier survival analysis stratified by presence of type A aortic dissection. When separated by indication for intervention, the survival of the group presenting with acute type A aortic dissection is poorer than that of the group presenting with other pathology. The 10-year survival for the type A group is $58.0 \% \pm 0.4 \%$ and contrasts with the non-type A group at $69.1 \% \pm 0.4 \%(\log \operatorname{rank} P=.003)$. 

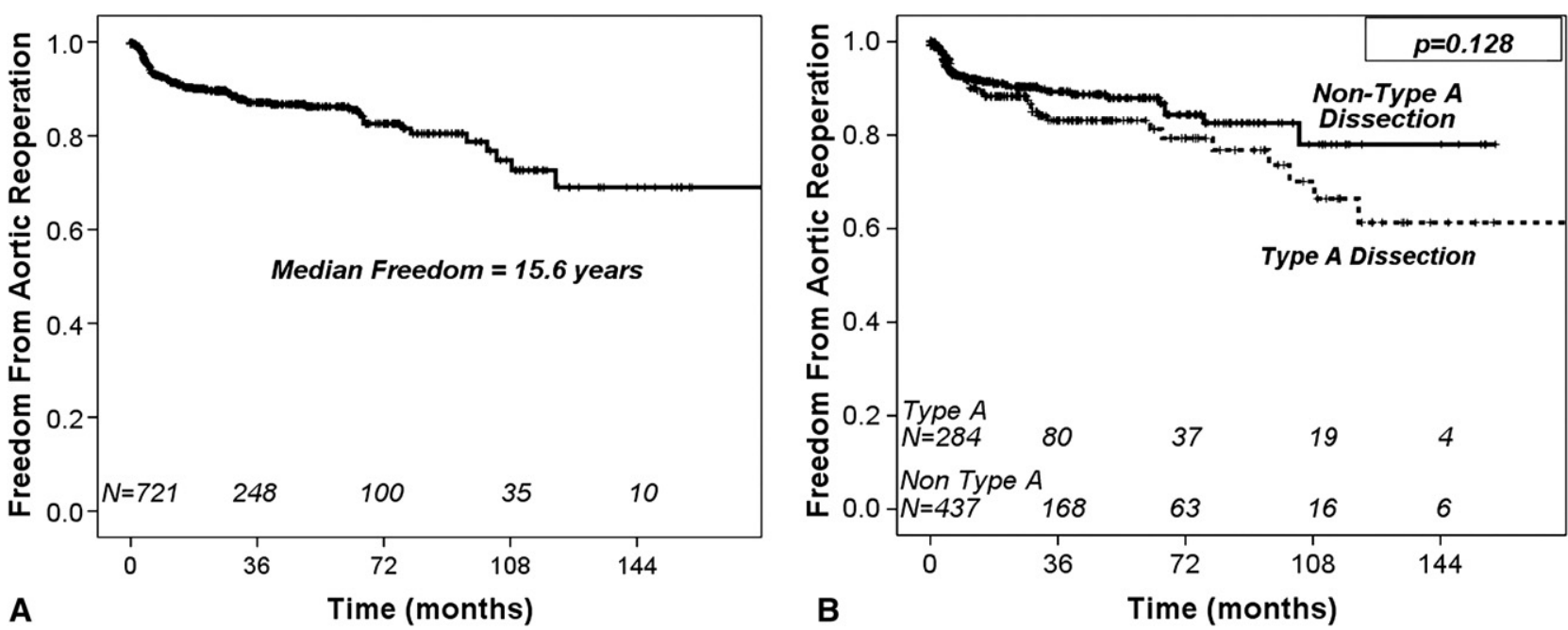

FIGURE 3. A, Kaplan-Meier analysis of late aortic events. Freedom from late aortic reoperation at any segment was $72.6 \% \pm 0.4 \%$ at 10 years. Although risk for late reoperation was not significantly different between type A and non-type A pathologic groups (B, $\log$ rank $P=.128)$, examination of the data suggests that the curves separated early and that more robust patient numbers with longer follow-up may demonstrate a difference.

correlate with postoperative stroke (all $P>.3$ ). Although the benefits of ACP continue to be debated, an alternative hypothesis for this lack of difference in the current study may be a selection bias favoring use of ACP in extended arch resection and preventing prolonged ( $>60$ minutes) cerebral ischemic times. ${ }^{16-19}$ Indeed, the mean cerebral ischemic times were relatively short (mean, $16.6 \pm 14.0$ minutes; range, 0-67 minutes). When contrasted with the mean lower body circulatory arrest times of $36.6 \pm 15.6$ minutes, this suggests that an aggressive strategy of using ACP in this instance may diminish the risk of stroke. This is particularly relevant given the classic work by Svensson and colleagues ${ }^{3}$ suggesting increasing risk for stroke with HCA times exceeding 40 minutes. As reported by others, this suggests moderate hypothermia (temperatures, $22^{\circ} \mathrm{C}-$ $25^{\circ} \mathrm{C}$ ) with cerebral perfusion may be well tolerated.

Late results in this study suggest that preoperative factors, such as age, impaired renal function, and prior coronary artery bypass grafting, predict late mortality and identify groups of patients who may be ideal for an endovascular solution. The identification of prolonged lower body circulatory arrest times is likely a surrogate for pathology that was more extensive or difficult to reconstruct. Estrera and colleagues ${ }^{12}$ have suggested similar results with their identification of the intraoperative variable of cardiopulmonary bypass times as predictive of late mortality. Late reoperations on the aorta were protected by concomitant aortic valve or root replacement. This was also a surprising finding and differs when compared with data from Sabik and colleagues ${ }^{14}$ and Estrera and colleagues, ${ }^{12}$ and thus deserves validation in future work. A closer evaluation of the actual reoperative procedures finds that the majority $(79.3 \%)$ are repairs of the descending or thoracoabdominal aorta, which may relate to the higher frequency of aortic dissection treated in this study when compared with that of Estrera and colleagues. Indeed, when stratified by operative procedure for type A dissection, freedom from reoperation was lower in the dissection group. Although not statistically significant, examination of the Kaplan-Meier curves reveals that these lines diverge early and remain separated thereafter, suggesting that either larger sample size or longer follow-up may reveal otherwise.

It is important to note that TEVAR was not appropriate for the majority of patients treated in this study, primarily because of the pathology treated (eg, type A dissection) or the anatomic constraints related to the proximity of aortic valve or arch branch vessels (eg, root, ascending, and proximal arch aneurysm). From 1993 to 2005, TEVAR was typically performed only in the setting of distal arch fusiform or saccular aneurysms or type B aortic dissections. Since 2005, the alternatives of hybrid arch debranching with TEVAR or, more recently, TEVAR with the "snorkel" branch vessel technique have been used primarily in patients considered too high risk for open aortic repair. Despite our long experience with TEVAR at the University of Michigan, we have not fully embraced the notion of endovascular repair with arch debranching as a substitute in all patients presenting with arch aneurysms. This partly stems from our positive experience with open repair as reported in this article. The second and equally important reservation is based on the unknown long-term durability of TEVAR in the unfavorable ascending and arch aortic configuration. Finally, as the Stanford group ${ }^{20}$ has also suggested in their analysis of patients presenting with bicuspid aortic valve and ascending aneurysms, a majority of patients will have enlargement in the root and proximal ascending aorta, 
where the complex anatomy of the sinuses, sinotubular junction, and coronary ostia make TEVAR with debranching procedures or branched endografts unfeasible with current technology. Their work suggests that in identifying an endovascular solution to the ascending aorta, a valved conduit addressing the coronary arteries may need to be considered as an option.

\section{Study Limitations}

Limitations of this study include its retrospective nature over a long study period. Small differences in operative technique and perioperative care may have affected outcomes, although this was not borne out after statistical analysis based on era of operation. Another limitation included the lack of complete follow-up with regard to secondary outcome of reoperation. However, the robust sample size and long interval of the study may have mitigated the effects of this limitation.

\section{CONCLUSIONS}

We have presented one of the largest series of open repair of aortic arch pathology reported in the literature. Our data suggest that this once dreaded clinical scenario can be addressed with low rates of morbidity and need for reoperation in the treated segments. As the therapy of aortic disease evolves into a more endovascular-based approach, certain subgroups of patients, such as those with advanced age or impaired renal function, emerge as ideal candidates for this application of newer technology.

\section{References}

1. DeBakey ME, Cooley DA, Crawford ES, Morris GC Jr. Successful resection of fusiform aneurysm of aortic arch with replacement by homografts. Surg Obstet Gynecol. 1957;105:656-64.

2. Griepp RB, Stinson EB, Hollingsworth JF, Buehler D. Prosthetic replacement of the aortic arch. J Thorac Cardiovasc Surg. 1975;70:1051-63.

3. Svensson LG, Crawford ES, Hess KR, Coselli JS, Rankin S, Shenaq SA, et al. Deep hypothermia with circulatory arrest: determinants of stroke and early mortality in 656 patients. $J$ Thorac Cardiovasc Surg. 1993;106:19-28.

4. Patel HJ, Williams DM, Shillingford MS, Dasika NL, Proctor MC, Deeb GM. Long term results from a 12 year experience with endovascular therapy for thoracic aortic disease. Ann Thorac Surg. 2006;82:2147-53.

5. Criado FJ, Clark NS, Barnatan MF. Stent graft repair in the aortic arch and descending thoracic aorta: a 4-year experience. J Vasc Surg. 2002;36:1121-18.

6. Dake MD, Miller DC, Semba CP, Mitchell RS, Walker PJ, Liddell RP. Transluminal placement of endovascular stent-grafts for the treatment of descending thoracic aortic aneurysms. N Engl J Med. 1994;331:1729-34.

7. Szeto WY, Bavaria JE, Bowen FW, Woo EY, Fairman RM, Pochettino A. The hybrid total arch repair: brachiocephalic bypass and concomitant endovascular aortic arch stent graft placement. J Card Surg. 2007;2:97-102.

8. Ferreira M, Chuter T, Harley D, Laniotti L, Abuhadha G, Monteiro M, et al. Hybrid repair of aortic arch aneurysms: a totally extrathoracic approach with branched endografts in two patients. Vascular. 2007;15:79-83.

9. Patel HJ, Williams DM, Upchurch GR, Dasika NL, Deeb GM. A comparative analysis of open and endovascular repair of the ruptured descending aorta. J Vasc Surg. 2009;50:1265-70.

10. Patel HJ, Williams DM, Upchurch GR, Dasika NL, Passow MC, Prager RL, et al. A comparison of open and endovascular descending thoracic aortic repair in patients older than 75 years of age. Ann Thorac Surg. 2008;85:1597-603.

11. Coselli JS, Buket S, Djukanovic B. Aortic arch operation: current treatment and results. Ann Thorac Surg. 1995;59:19-26.
12. Estrera AL, Miller CC 3rd, Porat E, Mohamed S, Kincade R, Huynh TT, et al. Determinants of early and late outcome for reoperation of the proximal aorta. Ann Thorac Surg. 2004;78:837-45.

13. Deeb GM, Jenkins E, Bolling SF, Brunsting LA, Williams DM, Quint LE, et al. Retrograde cerebral perfusion during hypothermic circulatory arrest reduces neurologic morbidity. J Thorac Cardiovasc. 1995;109:259-68.

14. Sabik JF, Lytle BW, Blackstone EH, McCarthy PM, Loop FD, Cosgrove DM. Long term effectiveness of operations for ascending aortic dissection. $J$ Thorac Cardiovasc. 2000;119:946-62.

15. Estrera AL, Miller CC 3rd, Lee TY, Shah P, Safi HJ. Ascending and transverse aortic arch repair; the impact of antegrade cerebral perfusion. Circulation. 2008;118:S160-6.

16. Okita Y, Minatoya K, Tagusari O, Ando M, Nagatsuka K, Kitamura S. Prospective comparative study of brain protection in total arch replacement: deep hypothermic circulatory arrest with retrograde cerebral perfusion or selective antegrade cerebral perfusion. Ann Thorac Surg. 2001;72:72-9.

17. Milewski RK, Pacini D, Moser GW, Moeller P, Cowie D, Szeto WY, et al. Retrograde and antegrade cerebral perfusion: results in short elective arch reconstructive times. Ann Thorac Surg. 2010;89:1448-57.

18. DiEusanio M, Schepens MA, Morshuis WJ, Dossche KM, DiBartolomeo R, Pacini D, et al. Brain protection using antegrade cerebral perfusion: a multicenter study. Ann Thorac Surg. 2003;76:1181-8.

19. Halkos ME, Kerendi F, Myung R, Kilgo P, Puskas JD, Chen EP. Selective antegrade cerebral perfusion via right axillary artery cannulation reduces morbidity and mortality after proximal aortic surgery. J Thorac Cardiovasc Surg. 2009; 138:1081-9.

20. Fazel SS, Mallidi HR, Lee RS, Sheehan MP, Liang D, Fleischman D, et al. The aortopathy of bicuspid aortic valve disease has distinctive patterns and usually involves the transverse aortic arch. J Thorac Cardiovasc Surg. 2008;135:901-7.

\section{Discussion}

Dr Alberto Pochettino (Philadelphia, $\mathrm{Pa}$ ). An outstanding presentation from master surgeons. It is particularly impressive to me that you have a $100 \%$ follow-up. I am somewhat envious of that. I found as I reviewed the article that you provided to me that your use of RCP and selective antegrade perfusion was sensible in my mind and very safe, which led to the outstanding results. I have a couple of comments.

The first one relates to using the data that you have from this series as a benchmark against which newer techniques can be measured. The majority of your reconstruction involved aortic root reconstruction in what we would call arch hemi or arch total arches. That group, even with today's technology, is not amenable, I don't think, to hybrid reconstruction. So I think it would make sense to look at the isolated arches or isolated arches plus descending reconstruction that you had and use that group, which accounts for approximately $13 \%$ of your patients, as a benchmark against which the arch hybrid should be compared. Do you have data on that group?

Dr Patel. We have not separated the analysis out specifically on that basis, but we appreciate your comments, understanding the current limitations of endograft technology. However, we do know that endograft technology is progressing to the ascending aorta and may soon include ascending and root procedures as well, and we believe that these data should be compared with contemporary open surgical procedures, such as that described here. But we fully understand and appreciate your comments.

Dr Pochettino. My next comment is about aortic dissection. As you know, I have come to use what has been described as a frozen elephant trunk in the treatment of acute type A dissection. You have a large series of patients with type A dissection, and it would be useful again as a comparison against which we should look at 
newer technology at the patients undergoing the DeBakey 1 procedure and how they fare both in terms of freedom from reoperation and survival. Do you have data on the DeBakey 1 cohort?

Dr Patel. We did not stratify the analysis based on extent of dissection. Just having been involved in a few of these procedures, I can suggest to you that a majority of these patients truly had dissections that extended throughout the aorta, but unfortunately I do not have that separate analysis as you have requested.

Dr Pochettino. One last question. I noticed from your article that you have changed your total arch reconstruction from an island to individual segments, to either all 3 of the vessels or at least 2. Have you noticed a decrease in the stroke rate as you changed your technique?

Dr Patel. That is a great question. Unfortunately, I did not separate this out into the island versus the individual bypass graft technique. We will tell you, as probably other surgeons have described, some of the bleeding risks may be less with the individual bypass technique, and we evolved toward that. My senior partner, Mike Deeb, evolved toward that when I was a resident in 2001, and since then we have virtually exclusively used the multibranch grafts that are available to us.

Dr Pochettino. Outstanding series.

Dr John Ikonomidis (Charleston, SC). Himanshu, congratulations on a beautifully presented study of a large population of aortic arch reconstructions. I have a 2-part question for you. I wonder if it is really appropriate when one considers stroke rates to group hemi-arch replacements with total arch replacements, because I think technically they are 2 different operations. An aortic arch reconstruction involves more manipulation of the great vessels, and one would expect intuitively that it would be associated with a higher stroke rate, and therefore including hemi-arches in the analysis would somewhat buffer that effect. My first question is, did you separate out hemi-arches from full arches, and what were the relative stroke rates in those? Related to that, did you include requirement for total arch replacement in your multivariable analysis to see if that was an independent predictor of stroke?

Dr Patel. When we analyzed the incidence of stroke, we did include the extent of resection in that analysis, and as a surrogate, extension into the descending aorta was identified as an independent risk factor for stroke. However, whether we used 1, 2, or 3 bypasses really did not separate out on univariate or multivariate analysis as a risk factor for stroke.

I will tell you that in our series, the neuroprotection strategy, whether it was just isolated RCP or a combination of RCP and ACP, really did not make a difference whether we saw postoperative stroke or not, and I suspect that it is partly because it is drowned in the numbers, because the bias obviously is that when we extended to a total arch repair, we would typically use ACP. If you look at the cerebral ischemic times that were calculated out for each patient, the cerebral ischemic time for the entire cohort was approximately 15 or 16 minutes, whereas the total lower body circulatory arrest time was approximately 30 to 35 minutes. So a significant proportion of patients did have an antegrade cerebral approach, and perhaps that may have mitigated the effects of extended arch reconstruction and its effects on stroke as well.

Dr Ali Khoynezhad (Omaha, Neb). Himanshu, that was an excellent presentation with great results. A question about a subset (the patients with type A aortic dissection): Not surprisingly, they had a higher early mortality, reoperation, and probably a higher stroke rate. Did you look into different cannulation sites, such as femoral or axillary cannulation for HCA, and did you find any difference in outcome of those patients? Also, was there any difference in outcomes by using transcranial Doppler? I adopted it early on, and this was before, especially since Dr Safi's group showed improvement of outcomes by utility intraoperative modification of the cannulation site when patients went on or came off pump to reduce cerebral malperfusion.

Dr Patel. We typically do not use other adjunctive maneuvers to determine whether there are changes in cerebral perfusion, such as cerebral oximetry and so on. The cannulation strategy in acute type A dissection evolved throughout the study. The majority of patients early on, and I would say until about 2005 or so, were cannulated usually through femoral access in the setting of acute type A dissection. In the setting of elective aneurysm or urgent aneurysm repair, if the pathology allowed it, meaning if it wasn't very calcified or so on, we would usually cannulate the ascending aorta and go on bypass that way. We have done axillary perfusion in a smaller number of patients who presented with an acute type A dissection, but that is more recently, within the last 3 or 4 years. I unfortunately don't have the data separating it out on the basis of cannulation site as a marker for stroke, but I do understand that there has been literature prescribing axillary approaches to reduce the risk of stroke.

Dr Anthony Estrera (Houston, Tex). Himanshu, a nice job. I think one of the deceptive things when you present your data is your late reintervention rate, because the reality is how many of these patients you had to reintervene for the arch portion of the graft, because if you are going to compare this with endovascular therapies, one of the main limitations with endovascular therapies are all these endoleaks related to the graft. The reality is most of your late reinterventions are related to progression of disease distal to your arch graft, and I would presume that your arch repairs are very durable. So if you could present some of that data, I think it would be helpful when you are comparing it as a contemporary series.

Dr Patel. If I remember correctly in the analysis, there may have been only 1 person who underwent reoperation in this entire series that we know of who had an anastomotic issue, and that was a patient who actually came in with an infected proximal suture line and developed a pseudoaneurysm requiring a root and partial ascending reconstruction. But you are absolutely correct, the majority of late reoperations are secondary to progression of disease in other aortic segments, not the treated aortic segment, as you would expect. 